\title{
10. Evaluating agency responses: the comprehensiveness and impact of whistleblowing procedures
}

\author{
Peter Roberts ${ }^{1}$
}

\section{Introduction}

What does the empirical evidence about whistleblowing in Australian public sector agencies, described in Part 1 of this book, say about the quality of their systems and procedures? So far in this part, analysis has focused on the attitudes and knowledge of managers, internal investigation systems and systems for protecting and managing whistleblowers (Chapters 7, 8 and 9). This chapter present an overall picture of how the reporting of wrongdoing is formally dealt with from an organisational perspective, examining and comparing the totality of agencies' procedures using the empirical evidence of key whistleblowing outcomes in the agencies studied.

As is already clear, many public sector organisations have accepted the challenge of encouraging staff to disclose perceived wrongdoing and have committed themselves to protecting staff from reprisals - but some have not, and most are finding at least some parts of the challenge to be substantial. From the outset, it is worth noting the three broad (and overlapping) themes, encountered by the researchers to date, which appear to drive organisational approaches to the management of whistleblowing. These themes demonstrate that the same challenges can be viewed differently by different managers and can help explain differences in agency approaches.

The first theme is compliance: many senior managers are aware that they are required to establish procedures and implement policies for the purpose of complying with applicable legislation, such as 'public interest disclosure' or 'whistleblower protection' legislation. Chapter 7 highlighted, however, that when it comes to basic management knowledge of statutory obligations and therefore their effective implementation, challenges begin to arise.

The second theme is utilitarian: many senior managers in organisations recognise that good governance requires that wrongdoing be identified and dealt with. A second dimension of this response is that managers might also recognise that when reporting wrongdoing results in individual staff members suffering mistreatment or reprisals, the potentially devastating effects on individuals, along with impacts on the productivity of others, can put large resource burdens on the organisation. 
Finally, senior managers in organisations often also take an ethical stance, viewing reporting of wrongdoing as a fundamental part of maintaining the integrity of the organisation. Those managers will work to establish whistleblowing systems and procedures for the reason that these promote integrity within the organisation as a whole, maintain public integrity more generally and perhaps also provide for fairer outcomes for individuals through the type of organisational justice described in Chapter 3.

This chapter analyses the contents and apparent effectiveness of agency procedures, in their legislative and jurisdictional context, in light of these three themes. The first part of the chapter looks for evidence from the employee survey of whether the existence of whistleblowing legislation is associated with desired outcomes from whistleblowing, at any agency level. These analyses provide some measure of the impacts when agencies rely simply on the existence of legislation to provide guidance to their staff about responses to whistleblowing or limit their approach to minimal compliance. The existence of legislation is measured subjectively, in terms of the level of staff awareness and confidence in that legislation within individual agencies. The outcomes measured are the reporting and inaction rates in those agencies (the proportion of employees who observe wrongdoing but do and do not report it) and the proportion of reporters who complain of mistreatment.

The results show that in those agencies in which more staff are aware of and confident about whistleblowing legislation, there are more positive attitudes to whistleblowing, higher whistleblowing 'propensity' on the part of staff, higher trust in the anticipated management response to whistleblowing and a higher likelihood that serious wrongdoing will be exposed or 'flushed out' (lower inaction rates). While these results suggest that even a 'mere compliance' approach can have positive effects, they also reveal some of its limitations. Despite these outcomes, the same agencies did not record any lower rates of mistreatment of reporters than other agencies. This suggests that while increased awareness of legislation encourages staff to report and to trust their management, more is needed for agencies to meet these raised expectations.

The second part of the chapter examines the comprehensiveness of procedures across the 175 agencies that provided written procedures to the study and the 102 of these agencies that also participated in the employee survey. These procedures provide the main framework within which organisations deal with, and respond to, reports of wrongdoing, at a level below or even irrespective of the framework provided by the legislation. The comprehensiveness of the procedures is assessed against the basic requirements of the relevant Australian Standard and also an extended set of requirements developed for the public sector by this project. 
The results show that while some areas in current procedures have some strength, there are systemic weaknesses in all jurisdictions in how agencies currently formally respond to whistleblowing. Only five of the 175 agencies were rated as having procedures that would reasonably satisfy all the requirements set out in the current Australian Standard. The substantial variability in the comprehensiveness of procedures found across all jurisdictions, together with their patchiness and generally low comprehensiveness, confirm the need for the development of new best-practice or model procedures. Consistent with the results from Chapter 9, the analysis reveals that agencies' formal procedures appear to be skewed towards encouraging reporting and setting in place the investigative responses to those reports, more than management of the welfare of those involved. The results also suggest a need for clearer statutory requirements and oversight of the quality of procedures. Even when agencies have moved beyond a mere compliance approach and have taken up a more utilitarian approach, this appears to remain limited in its focus.

The third part of the chapter examines the effectiveness of current procedures and establishes that more comprehensive procedures are indeed associated with a higher incidence of positive outcomes from whistleblowing. These results indicate that a more comprehensive approach is likely to deliver results for agencies - not only in terms of heightened support for whistleblowing and trust in management, but in substantive outcomes such as reporting rates and reduced rates of whistleblower mistreatment. The general weakness of most procedures for the protection of whistleblowers means that these outcomes cannot be traced directly to better whistleblower support programs. Nevertheless, the evidence suggests that more comprehensive approaches do yield better outcomes, providing significant encouragement for those agencies prepared to make an effort to develop better whistleblowing management systems.

\section{Awareness of, and confidence in, legislation}

As reviewed throughout this book, and discussed in more detail in Chapter 11 , in each jurisdiction the management of whistleblowing takes place in a specific legislative context. In each case, whistleblowing or 'public interest disclosure' legislation sets in place different requirements for agency-level procedures and different frameworks for ensuring or increasing the likelihood of agency compliance. The adequacy of these legislative frameworks is assessed in the next chapter, in light of all the evidence.

An important issue is whether the existence of whistleblowing legislation has any direct impact on reporting behaviour and other outcomes in the agencies studied. This is especially salient given the importance of legislative obligations to those agencies taking simply a compliance approach to their whistleblowing procedures and systems. Despite the differences in the legislative frameworks, they share the objectives of facilitating disclosures about wrongdoing by public 
employees, ensuring that disclosures are properly dealt with and ensuring whistleblowers are protected from reprisals or mistreatment. At a general or symbolic level, therefore, the impacts of these regimes on public officials' behaviour should be broadly comparable.

The following sections examine first the levels of awareness of legislation within agencies and second the differing levels of confidence in that legislation. The focus of this analysis is not the accuracy of employees' beliefs, but how their beliefs might influence attitudes, behaviour and outcomes.

\section{Awareness of legislation}

In Chapter 7 (Table 7.5), it was seen that 44 per cent of all employee survey respondents believed they were subject to legislation covering their 'rights and responsibilities associated with reporting alleged wrongdoing', while very few ( 2 per cent) believed they were not covered and a very large proportion (54 per cent) did not know. Earlier, in Chapter 3, it was seen that awareness of and opinions about the relevant legislation did not differ significantly between the employees who reported wrongdoing and those who observed wrongdoing but did not report it. This could suggest that the presence of legislation or employees' views of its contents make no difference; however, further analysis shows that the picture is more complex.

Table 10.1 sets out the relationship between whether or not respondents to the employee survey believed they were covered by legislation and how they answered the questions designed to establish their attitudes to whistleblowing, or their level of whistleblowing propensity. The table shows the relationship for all respondents divided into four groups according to their reporting behaviour. The table shows a very strong correlation between the belief that an employee is covered by relevant legislation and the likelihood that they will blow the whistle according to the whistleblowing-propensity scale. This correlation was present for all groups - including, as seen in Chapter 3, those who observed wrongdoing but did not report the most serious instance.

These results suggest either that the (perceived) presence of legislative obligations and protection is a strong contributing factor to employees' positive attitude to blowing the whistle or that those who have a positive attitude to blowing the whistle assume that they are subject to legislative obligations and protection. In either case, irrespective of how their beliefs influence their real reporting behaviour, there is an important relationship between the presence of legislation and employees' expectations about what should happen if they disclose wrongdoing. 
Table 10.1 Relationship between awareness of legislation and whistleblowing propensity

\begin{tabular}{ll}
\hline Group of employees (by reporting behaviour) & $\begin{array}{l}\text { Correlation between awareness of legislation and } \\
\text { whistleblowing propensity }\end{array}$ \\
\hline Non-observers of wrongdoing $(\mathrm{n}=2074)$ & Pearson correlation $=-0.39^{*}$ \\
Observers but non-reporters $(\mathrm{n}=3198)$ & Pearson correlation $=-0.35^{* *}$ \\
Role reporters $(\mathrm{n}=583)$ & Pearson correlation $=-0.37^{* *}$ \\
Non-role reporters $(\mathrm{n}=1427)$ & Pearson correlation $=-0.35^{* *}$ \\
\hline All respondents $(\mathrm{n}=7310)$ & Pearson correlation $=-0.38^{* *}$ \\
\hline
\end{tabular}

* correlation is significant at the 0.05 level

** correlation is significant at the 0.01 level

Notes: Correlations are negative because the awareness rating specifies awareness as scoring low and a lack of awareness as scoring high. The whistleblowing-propensity scale ranges from low propensity scoring lowest to high propensity scoring highest.

Source: Employee survey: Q15, Q16.

To better examine whether awareness of legislation also translates into real whistleblowing behaviour, analysis was conducted comparing the results between different agencies. As shown in Chapter 7 in relation to managers, there were significant jurisdictional differences in the proportion of respondents who believed they were covered by legislation. Figure 10.1 shows the number of agencies in each jurisdiction according to the differing proportions of their employees who believed they were covered. There is even greater variation at an agency level. Some of the variation is probably explained by variations in the legal reality - for example, many Commonwealth Government agencies operate outside the framework of the Public Service Act 1999 (Cth), which provides the only legislative provision relevant to whistleblowing. This could explain why some Commonwealth agencies showed lower percentages of employees believing they were covered by legislation; the fact is that many were not. It does not, however, explain the large number of state agencies in the same category, since almost all were covered by legislation at the time.

Table 10.2 shows whether, at an agency level, there was any relationship between the proportion of employees who believed they were covered by legislation and a number of the key outcomes discussed earlier in Chapters 2 and 5. These are: the overall trust of employees in how management would respond to whistleblowing in that agency; the proportion of employees who did not report or take other action (inaction rate); the proportion of employees who reported the most serious wrongdoing they saw (reporting rate); and the proportion of those who reported who indicated they were then treated badly, either by management or by co-workers. 
Figure 10.1 Awareness of legislation by agency and jurisdiction

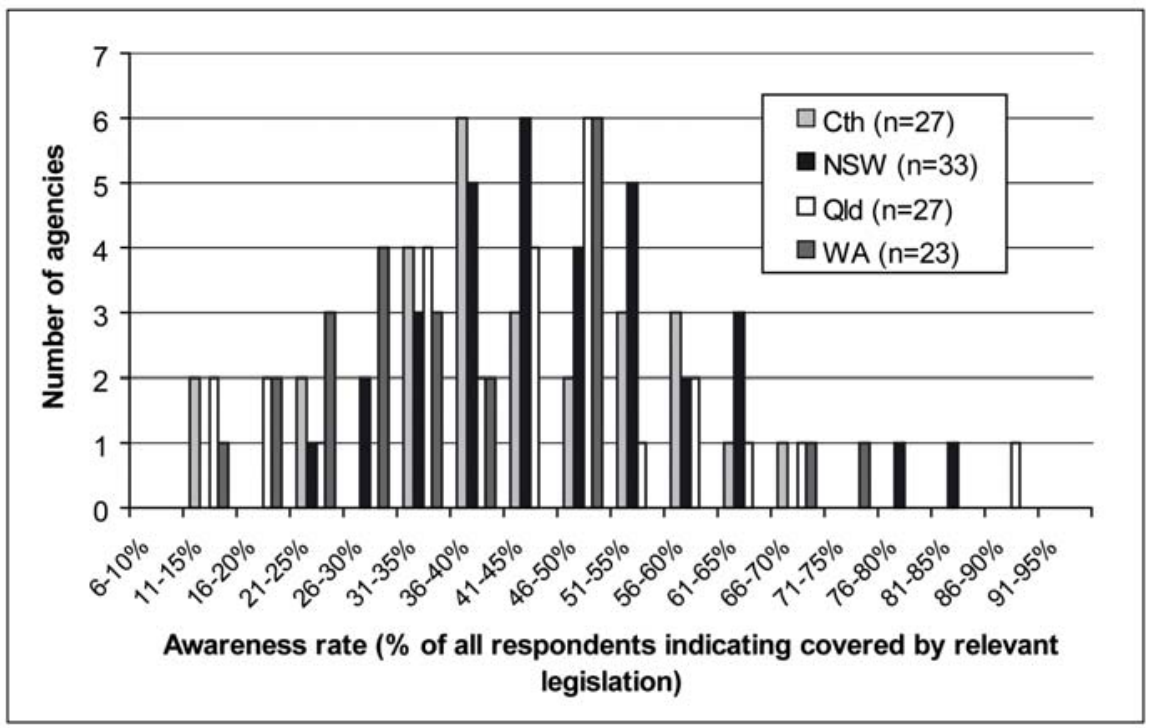

Source: Employee survey: Q16.

Table 10.2 Relationship between legislation awareness and reporting and outcome measures (agencies)

Measures from employee survey

Correlation with legislation awareness rate (016)

1) Mean agency rating for how management would respond Pearson correlation $=0.25^{*}$

to report of wrongdoing (Q18 as a 13 -item scale) $1=$ poor Significance (two-tailed) $=0.008$

and $5=$ well

$(\mathrm{n}=110)$

2) Inaction rate: proportion of respondents who observed Pearson correlation $=-0.05$

wrongdoing they believed to be very/extremely serious but Significance (two-tailed) $=0.640$

did not report, did not deal with by self and it was not reported by someone else $(026,035)^{a}$

$(\mathrm{n}=86)$

3) Reporting rate: proportion of respondents who observed Pearson correlation $=0.16$

wrongdoing they believed to be very/extremely serious and reported it $(\mathrm{Q} 26)$

Significance (two-tailed) $=0.142$

( $\mathrm{n}=86)$

4) Proportion of all non-role reporters who rated treatment Pearson correlation $=0.17$ by management as 'bad' or 'extremely bad' (Q30)

Significance (two-tailed) $=0.222$

( $\mathrm{n}=52)$

5) Proportion of all non-role reporters who rated treatment Pearson correlation $=0.08$

by co-workers as 'bad' or 'extremely bad' $(031)^{\mathrm{a}}$

Significance (two-tailed) $=0.556$

( $\mathrm{n}=51$ )

* correlation significant at the 0.01 level

a It was anticipated that these correlations would be negative because these outcome scales run from a good outcome scoring lowest to a poor outcome scoring highest. 
A significant relationship was found only on the first measure. Similar to the result for whistleblowing propensity, agencies that had higher proportions of employees who believed they were covered by legislation also had higher proportions of staff who believed that management's response to whistleblowing would be positive, including protection of their rights if they suffered reprisals. In other words, while there is no evidence that the simple belief that legislation applies has any direct influence on reporting behaviour, this belief does go hand-in-hand with employees' confidence in management reaction and support. Whistleblowing legislation appears to do at least one thing for which it was intended: it increases employees' expectations that they will be taken seriously and will be protected if they blow the whistle. This has immediate implications for agencies that seek to discharge their whistleblowing management obligations simply by telling their employees about the legislation that applies.

\section{Confidence in legislation}

Even if they are aware of the legislative protections and obligations they think apply, how confident are employees in them? Confidence in legislation was gauged using four items in the employee survey already introduced in Chapter 7 , in which the confidence of managers and non-managers was compared. These items are shown in Table 10.3, with results according to jurisdiction. For those who believed they were covered by legislation, confidence in it was highest among Commonwealth respondents and lowest among Queensland respondents. This is an interesting result, since Queensland has been assessed as having the most comprehensive legislation and the Commonwealth the least comprehensive (Brown 2006).

For contrast, Table 10.4 shows how case-handlers and managers in the case study agencies answered when asked a similar question about their confidence in the legislation. Given that this survey was targeted towards participants who had experience of the issues, it would be expected that their understanding of the legislation would be deeper than the random sample of employees. Here again, as in Table 10.3, the Commonwealth participants reported higher levels of confidence, even though the Commonwealth had the least comprehensive legislative cover. The average opinions of NSW and West Australian case-handlers and managers closely or exactly match the level of confidence held by the average employee in these jurisdictions. The Queensland results are again divergent, with case-handlers and managers having a significantly higher level of confidence than the average employee. 
Table 10.3 Confidence in legislation by jurisdiction (means)

\begin{tabular}{|c|c|c|c|c|}
\hline $\begin{array}{l}1=\text { strongly disagree } \\
5=\text { strongly agree }\end{array}$ & $\begin{array}{c}\text { Cth } \\
(\mathrm{n}=1085)\end{array}$ & $\begin{array}{c}\text { NSW } \\
(\mathrm{n}=1319)\end{array}$ & $\begin{array}{c}\text { Old } \\
(\mathrm{n}=925)\end{array}$ & $\begin{array}{c}\text { WA } \\
(\mathrm{n}=418)\end{array}$ \\
\hline $\begin{array}{l}\text { The existence of the legislation makes it easier } \\
\text { for me to consider reporting corruption }\end{array}$ & 3.64 & 3.66 & 3.56 & 3.53 \\
\hline $\begin{array}{l}\text { I am confident that the legislation has the power } \\
\text { to protect me from any negative consequences } \\
\text { if I were to report corruption }\end{array}$ & 3.13 & 3.05 & 2.96 & 3.10 \\
\hline I believe that the legislation is ineffective ${ }^{a}$ & 2.69 & 2.78 & 2.84 & 2.80 \\
\hline $\begin{array}{l}\text { The legislation is in need of major change to } \\
\text { improve employee reporting of wrongdoing }\end{array}$ & 2.86 & 2.95 & 3.06 & 2.94 \\
\hline Overall mean & 3.30 & 3.24 & 3.15 & 3.22 \\
\hline $1=$ low, $5=$ high & $(n=1103)$ & $(n=1352)$ & $(n=942)$ & $(n=425)$ \\
\hline
\end{tabular}

${ }^{a}$ Items reverse scored

Source: Employee survey: Q17.

Table 10.4 Confidence in legislation: case-handlers and managers, by jurisdiction

\begin{tabular}{|c|c|c|c|c|}
\hline $\begin{array}{l}\text { Overall means } \\
1=\text { low }, 5=\text { high }\end{array}$ & Cth & NSW & Old & WA \\
\hline Case-handlers & $\begin{array}{c}3.26(\mathrm{n}= \\
94)\end{array}$ & $\begin{array}{c}3.07(n= \\
45)\end{array}$ & $\begin{array}{c}3.18(n= \\
29)\end{array}$ & $\begin{array}{c}3.05(\mathrm{n}= \\
36)\end{array}$ \\
\hline Managers & $\begin{array}{c}3.26(\mathrm{n}= \\
71)\end{array}$ & $\begin{array}{c}3.36(n= \\
64)\end{array}$ & $\begin{array}{c}3.39(n= \\
48)\end{array}$ & $\begin{array}{c}3.22(\mathrm{n}= \\
66)\end{array}$ \\
\hline Total & $\begin{array}{c}\mathbf{3 . 2 6} \\
(\mathrm{n}=165)\end{array}$ & $\begin{array}{c}\mathbf{3 . 2 4} \\
(\mathrm{n}=109)\end{array}$ & $\begin{array}{c}3.31 \\
(\mathrm{n}=77)\end{array}$ & $\begin{array}{c}\mathbf{3 . 1 6} \\
(\mathrm{n}=102)\end{array}$ \\
\hline
\end{tabular}

Sources: Case-handler and manager surveys: Q21.

Table 10.5 Trust in management response, and whistleblower treatment (means, by jurisdiction)

\begin{tabular}{|c|c|c|c|c|c|}
\hline Measures from employee survey & Cth & NSW & Old & WA & Total \\
\hline $\begin{array}{l}\text { How management would respond to report of } \\
\text { wrongdoing (Q18 as a } 13 \text {-item scale) } \\
1=\text { poor, } 5=\text { well }\end{array}$ & $\begin{array}{l}3.30 \\
(\mathrm{n}=2 \\
261)\end{array}$ & $\begin{array}{c}3.31 \\
(n=2 \\
517)\end{array}$ & $\begin{array}{c}3.23 \\
\text { (n }=1 \\
687)\end{array}$ & $\begin{array}{c}3.30 \\
(n=950)\end{array}$ & $\begin{array}{c}3.30 \\
(\mathrm{n}=7 \\
473)\end{array}$ \\
\hline $\begin{array}{l}\text { For all non-role reporters, treatment by } \\
\text { management } 1=\text { well, } 5=\text { poor }\end{array}$ & $\begin{array}{c}2.99 \\
(n=379)\end{array}$ & $\begin{array}{c}2.83 \\
\text { (n }=456\end{array}$ & $\begin{array}{c}2.99 \\
(n=339)\end{array}$ & $\begin{array}{c}2.87 \\
(n=144)\end{array}$ & $\begin{array}{c}2.92 \\
(\mathrm{n}=1 \\
325)\end{array}$ \\
\hline $\begin{array}{l}\text { For all non-role reporters, treatment by } \\
\text { co-workers } \\
1=\text { well, } 5=\text { poor }\end{array}$ & $\begin{array}{c}2.77 \\
\text { (n }=373\end{array}$ & $\begin{array}{c}2.59 \\
\text { (n }=44\end{array}$ & $\begin{array}{c}2.68 \\
(n=336)\end{array}$ & $\begin{array}{c}2.70 \\
(\mathrm{n}=1 \\
445)\end{array}$ & $\begin{array}{l}2.68 \\
(\mathrm{n}= \\
1304)\end{array}$ \\
\hline
\end{tabular}

Source: Employee survey: Q18, Q30, Q31. 
Evaluating agency responses: the comprehensiveness and impact of whistleblowing procedures

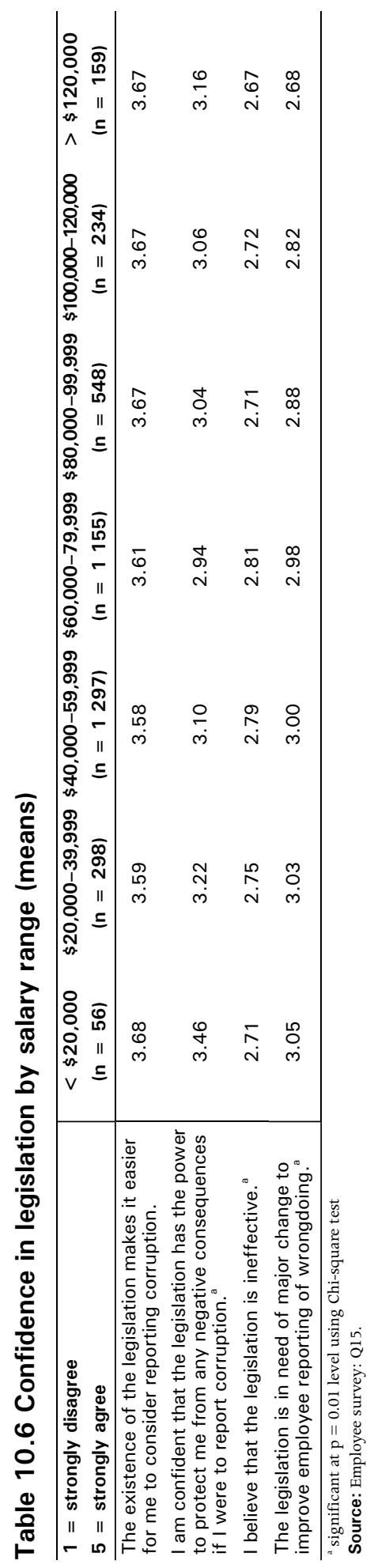


Before examining the possible effects of confidence in legislation, it is worth noting two further features of this evidence. First, the differences between the mean results, while still statistically significant, are nevertheless objectively small. The confidence means of all groups - in every jurisdiction and in most agencies - tend to hover around the midpoint of the scales, indicating large numbers of respondents who did not know or were unwilling to state a view about the content or effectiveness of the legislation. Thirty-eight per cent of all employee survey respondents could neither agree nor disagree that they were confident that the legislation had power to protect them, 52 per cent could not state a view about whether they thought it was effective and 57 per cent could not or would not say whether it needed major change. As seen in Chapter 7, respondents were generally very likely to agree they needed more information and training about the legislation.

It is also worth noting where confidence is lowest and highest. Table 10.6 shows the distribution of confidence according to salary range. As indicated in Chapter 7, managers tend to be more confident in the legislation than non-managers, but this table also shows that junior and/or part-time staff members are also likely to be more confident. The least confident employees are likely to be those in middle salary brackets ( $\$ 40,000-79,000$ per annum).

Overall, there is good reason to believe that confidence in legislation does correlate with some of the outcomes considered earlier. Even if simply being aware of legislation does not influence behaviour, differences emerge if employees are both aware and hold the legislation in either high or low regard. On the surface, Table 10.5 suggested a possible relationship, given basic results by jurisdiction. In at least one case in which confidence in the legislation ranked low-Queensland, as shown in Table 10.3 - there is also lower overall trust in the likely management response and some higher levels of reported mistreatment by managers.

Do these patterns hold statistically or at an agency level? Table 10.7 tests this by again looking for correlations at the agency level, comparing the level of confidence in legislation within specific agencies with their outcomes on the same five measures used earlier in relation to awareness. 


\section{Table 10.7 Relationship between employee confidence in legislation and reporting and outcome measures (agencies)}

\begin{tabular}{|c|c|}
\hline Measures from employee survey & Correlation with confidence in legislation \\
\hline $\begin{array}{l}\text { 1) Mean agency rating for how management would } \\
\text { respond to report of wrongdoing (Q18 as a } 13 \text {-item } \\
\text { scale) } \\
1=\text { poor and } 5=\text { well }\end{array}$ & $\begin{array}{l}\text { Pearson correlation }=0.62 * * \\
\text { Significance (two-tailed) }=0.0005 \\
(\mathrm{n}=92)\end{array}$ \\
\hline $\begin{array}{l}\text { 2) Inaction rate: proportion of respondents who } \\
\text { observed wrongdoing they believed to be } \\
\text { very/extremely serious but did not report, did not deal } \\
\text { with by self and it was not reported by someone else } \\
(026,035)^{\mathrm{a}}\end{array}$ & $\begin{array}{l}\text { Pearson correlation }=-0.23^{*} \\
\text { Significance (two-tailed) }=0.041 \\
(\mathrm{n}=83)\end{array}$ \\
\hline $\begin{array}{l}\text { 3) Reporting rate: proportion of respondents who } \\
\text { observed wrongdoing they believed to be } \\
\text { very/extremely serious and reported it (Q26) }\end{array}$ & $\begin{array}{l}\text { Pearson correlation }=0.15 \\
\text { Significance (two-tailed) }=0.165 \\
(\mathrm{n}=83)\end{array}$ \\
\hline $\begin{array}{l}\text { 4) Proportion of all non-role reporters who rated } \\
\text { treatment by management as 'bad' or 'extremely bad' } \\
(030)^{\mathrm{a}}\end{array}$ & $\begin{array}{l}\text { Pearson correlation }=-0.19 \\
\text { Significance (two-tailed) }=0.209 \\
(\mathrm{n}=51)\end{array}$ \\
\hline $\begin{array}{l}\text { 5) Proportion of all non-role reporters who rated } \\
\text { treatment by co-workers as 'bad' or 'extremely bad' } \\
(\mathrm{Q} 31)^{\mathrm{a}}\end{array}$ & $\begin{array}{l}\text { Pearson correlation }=-0.14 \\
\text { Significance (two-tailed) }=0.313 \\
(\mathrm{n}=51)\end{array}$ \\
\hline
\end{tabular}

* correlation is significant at the 0.05 level

** correlation is significant at the 0.01 level

${ }^{a}$ It was anticipated that these correlations would be negative because these outcome scales run from a good outcome scoring lowest to a poor outcome scoring highest.

A strong relationship was found only on the first measure (higher trust in management response to whistleblowing), with a somewhat lesser relationship on the second measure (lower inaction rate in response to serious wrongdoing). No significant relationship was found between the proportion of employees who were confident in the legislation and the reporting rate or the outcomes in terms of treatment in those agencies.

These nil results could nevertheless be important since they suggest that confidence in legislation is based primarily on its symbolic intent, rather than on any observable pattern in better (or worse) outcomes for whistleblowers. This reinforces the extent to which employees simply do not know what happens under the legislation. The results mean that while a high incidence of whistleblower mistreatment is not flowing through into negative views about the legislation, nor is good treatment of whistleblowers flowing through to bolster confidence.

The mixed results on reporting and inaction rates make it difficult to conclude that confidence in the legislation increases the level of reporting, at the agency level. Across the 83 agencies for which sufficient data exist to permit this analysis, however, the significant correlation between confidence and lower inaction rates suggests there is something about agencies in which this confidence is higher that does lead to wrongdoing being more likely to be dealt with or 'flushed out'. As levels of confidence in the legislation increased in an agency, the proportion of observers of serious wrongdoing who did nothing went down. As explained 
in Chapter 2, this is perhaps a better result than an increased reporting rate, since even if many people observe the same wrongdoing, all it takes is one or a few people to report or otherwise deal with it for action to be taken. It is plausible that in agencies with higher confidence in legislation, the perceived higher likelihood of someone reporting the wrongdoing is enough to induce action from those in positions of responsibility.

These results indicate that even at the current low level of knowledge of whistleblowing legislation among employees, awareness of and belief in that legislation can be associated with positive effects. The results clearly suggest that higher awareness of and confidence in whistleblowing legislation, at the agency level, help convince employees that their own management's response to whistleblowing can be trusted, including protection of their rights. In other words, the results point to the conclusion that employees who are confident they will be taken seriously and protected by management appear to assume that this is either required or reinforced by effective legislation - or vice versa. In organisations in which awareness and confidence of the legislation are higher, it is also generally more likely that serious wrongdoing will be brought to light.

These results indicate that even a mere compliance approach to whistleblowing by agency management, relying only on the simple existence and symbolic value of the applicable legislation, can yield some positive outcomes. These results also confirm, however, that, as yet, there is no evidence that legislation is helping deliver improved outcomes for whistleblowers themselves or reduced levels of conflict within organisations about the management of the process. Given that whistleblowing legislation appears to do at least one thing for which it was intended-increasing employees' expectations that they will be taken seriously and protected - the lack of evidence that it has the latter effect raises a serious challenge for agencies relying simply on compliance. Irrespective of the precise procedural requirements imposed on agencies by the legislation, even its simple existence-if known to staff-creates an obligation to develop effective procedures for managing the individuals involved. The alternative is that legislative frameworks will function simply as a 'trap', achieving their goals in encouraging employees to report but not meeting reasonable expectations regarding support and protection as a consequence of having done so.

The importance of agencies taking active measures to fill the gap between legislative requirements and their own needs is also reflected elsewhere in these results. It is notable that differences in the reality of legislative arrangements do not appear to impact on key results, such as the level of trust in management to handle reports among Commonwealth agencies, as shown in Table 10.5. The indications of how Commonwealth whistleblowers feel they were treated by management and co-workers similarly does not appear to have any direct relationship to the objectively weak legislative framework. In relation to 
treatment by management, the Commonwealth average is the same for one jurisdiction that does have comprehensive whistleblowing legislation. A similar pattern will emerge in relation to procedures. This confirms that, at an agency level, the relationship between legislation and procedures is not direct. Jurisdictions with relatively good legislation are not necessarily currently getting the desired results at an agency level, while even in jurisdictions with weaker legislation, some agencies can achieve-and are achieving-relatively good systems and results.

In thinking about the relationship between the procedures and the legislation, it is useful to keep in mind that organisations have available general employment powers that can fulfil many of the objectives of an effective whistleblower scheme. Clearly, specific legislation is necessary to provide a high level of protection against reprisals and the capacity for individuals to seek compensation. Having said that, there is still a considerable amount of discretion for organisations to develop procedures that go beyond legislative requirements.

This is particularly the case when it comes to the listing of concerns that can be brought forward in a whistleblowing procedure. As will be demonstrated below, some Commonwealth organisations effectively go beyond the very limited whistleblower regime in that jurisdiction and use general employment powers to encourage and protect staff reporting on a broader range of issues. Attempting to overlay specific legislative protections with a general employment authority is, however, quite complex. Care needs to be taken not to mislead staff into thinking that they have legislative protection against reprisal when their protection is based only on a general employment power.

\section{Comprehensiveness of policies and procedures}

If the comprehensiveness of legislation has been the subject of debate, what of the comprehensiveness of agency procedures for managing whistleblowing? To arrive at a better picture of the state of agency procedures, data were collected from 304 public sector agencies on their whistleblowing-related practices and procedures, via the agency survey. Seventy-three of these were Commonwealth agencies, including a mix of APS and non-APS agencies; while 85 were from New South Wales, 83 from Queensland and 63 were agencies of the West Australian Government. The aim was to collect comprehensive data on:

- $\quad$ policies and procedures relating to wrongdoing

- the investigation and assessment of disclosures (reviewed in Chapter 8)

- $\quad$ support and management of internal witnesses (reviewed in Chapter 9)

- reprisals against internal witnesses (reviewed in Chapter 9). 


\section{Table 10.8 Agency whistleblowing procedures: contents and mean score (maximum 3)}

\begin{tabular}{ll}
\hline Assessment item/topic & Mean
\end{tabular}

1. Ease of comprehension of document ${ }^{\mathrm{a}}$

2. To whom and how whistleblowing concerns can be directed (internally)

3. Reporting will be kept confidential and secure within the law ${ }^{a}$

4. Types of concerns for which it is appropriate to use the whistleblowing mechanism

5. Information about legislation ${ }^{\mathrm{a}}$

6. Investigation process to follow on receipt of a whistleblowing report

7. To whom and how whistleblowing concerns can be directed (externally) and in what circumstances $^{\mathrm{a}}$

8. Organisation's opinion of reporting wrongdoing through appropriate channels

9. Commitment to protect and respect internal witnesses ${ }^{b}$

10. Roles and responsibilities of the key players in the organisation

11. Commitment to principle of whistleblowing

12. A description of the protection of the rights of people against whom allegations have been made ${ }^{\mathrm{a}}$

13. Internal witnesses will receive feedback

14. Who may invoke the whistleblowing mechanism (that is, employees, contractors, the general public, and so on)

15. Staff who report wrongdoing not to suffer disciplinary action ${ }^{a b}$

16. How sure the internal witness should be of the truth of their concerns before invoking the whistleblowing mechanism

17. Active management and support of internal witnesses ${ }^{a b}$

18. Benefits and importance to the entity of having a whistleblowing mechanism

19. Anonymous reports will be acted on

20. Procedures for responding to reprisal action against internal witnesses ${ }^{a b}$

21. Sanctions for making a false or frivolous allegation ${ }^{a}$

22. Rights of the internal witness to request positive action by the entity to protect them ${ }^{b}$

23. Procedures for the investigation of reprisal action against internal witnesses ${ }^{a b}$

24. Procedures for the assessment of risk of reprisal against individual whistleblowers ${ }^{a b}$

\footnotetext{
${ }^{\mathrm{b}}$ Criterion relating directly or indirectly to whistleblower management and protection.
} 
As outlined in Chapter 9, 76 per cent (231) of the 304 agencies indicated that they had formal internal disclosure procedures. This figure was itself somewhat low, given that some non-APS Commonwealth agencies had procedures even when under no legislative obligation; many agencies that were under such an obligation provided responses clearly indicating that they were not fulfilling them. In all, 186 of the agencies surveyed indicated they had attached copies of their formal internal disclosure procedures. In fact, written procedures were received for only 175 agencies.

To allow a comparative assessment of the contents and the comprehensiveness of agencies' procedures, an instrument was developed by which their contents could be coded and rated. This procedures assessment involved examining the written procedures for their coverage of 24 items, or topics, listed in Table 10.8.

Fourteen of the items were drawn directly from the Australian Standard Whistleblower Protection Programs for Entities (AS 8004-2003). Ten items were added by the research team in light of issues of known importance in public sector agencies and the results of an initial project symposium held in July 2005. The identification of the essential criteria that go to make up effective whistleblowing procedures also followed the lead of a study of 57 private and 57 public sector organisations in the United Kingdom (Lewis 2002). In that study, 14 essential elements were identified, all of which were present in the procedures-assessment instrument developed in the present study. In a study for the European Parliament, Bjorn-Liebenau (2006) identified 18 key elements and these also closely matched the criteria used in this study.

Table 10.8 also sets out the mean score for each item across all 175 agencies, ranked in order of the overall strength or comprehensiveness of the criteria. Each mean reflects a rating of between 0 and 3, with the contents of procedures having been rated in one of two ways: statements of commitment or principle were rated according to strength $(0=$ no mention, $1=$ brief mention, $2=$ reasonably strong, 3 = extremely strong), while actual procedures were rated according to comprehensiveness $(0=$ no mention, $1=$ brief mention, $2=$ reasonably comprehensive, 3 = extremely comprehensive). Detailed guidance was given to the researchers involved in order to ensure consistency and to minimise variations in assessment approaches.

As seen in the table, there was great variation in the content of procedures, without any items being consistently strong right across all agencies. The overall weakness of the procedures, even on more frequent topics, is reflected in the fact that none of the strongest items even reached a score of 2 (reasonably strong/comprehensive). There was also great variation between those aspects that were treated well in procedures, on average, and those treated poorly. Many key issues were often either entirely omitted or dealt with far more scantily than others. In some cases, stronger items reflected the fact that many public sector 
agencies have procedures in place dealing with other issues, such as internal investigations, which are not focused on the management of whistleblowing but can be applied to that process. While investigatory capacity remains open to debate, as discussed in Chapter 8, the fact is that procedures exist. Similarly, most agencies responded to the imperative for procedures by setting out the process to be followed by people who came forward with reports (for example, who they should report to and what the recipient of the report should do).

The weaker items in Table 10.8 confirm the results presented in Chapter 9 regarding the absence and weakness of mechanisms for the protection and support of internal witnesses. The eight items relating directly or indirectly to management and protection of whistleblowers are also highlighted in the table. The weakness of many of these items confirms that active measures to support and protect internal witnesses remain the single greatest unmet challenge in the operational practices of agencies.

How do individual agencies compare in the comprehensiveness of their procedures?

The mean scores for all agencies in each jurisdiction are shown in Table 10.9. The results are shown, first, using simply the 14 items contained in the Australian Standard. Given 14 items, the maximum score for any agency on this measure was 42 , but the average score for all agencies was only 15.9. This low average score is of obvious concern, given that, if an assumption is made that a score of 2 (reasonably strong/comprehensive) is needed to meet a reasonable standard on any topic, the minimum score needed to meet the Australian Standard would be 28 out of 42 . Only five of the 175 agencies provided procedures that met or exceeded this standard.

The same table also shows the results using all 24 items in the more comprehensive assessment developed in this research. The outcome is similar. Given the 24 items, the potential maximum score for any agency was 72, but the average score across all agencies was only 24.4. Of course, there was significant variation between agencies, across the entire group and within each jurisdiction. The average score for the 15 case study agencies was substantially higher, at 36.2, reflecting the stronger organisational emphasis that many of these agencies have given to these issues. Nevertheless, the lowness of the scores is striking, confirming that, overall, few of the whistleblowing procedures submitted by agencies can be regarded as comprehensive. 
Table 10.9 Comprehensiveness of agency procedures (average scores)

\begin{tabular}{lccc}
\hline Jurisdiction & $\begin{array}{c}\text { Number of agencies } \\
\text { assessed }\end{array}$ & $\begin{array}{c}\text { Mean score out of 42 } \\
\text { Australian Standard } \\
\text { (standard deviation) }\end{array}$ & $\begin{array}{c}\text { Mean score out of 72 } \\
\text { WWTW (standard } \\
\text { deviation) }\end{array}$ \\
\hline Commonwealth & 56 & 14.5 & 24.5 \\
New South Wales & 60 & $(8.23)$ & $(11.08)$ \\
Queensland & 31 & 18.3 & 27.4 \\
& & $(4.96)$ & $(7.61)$ \\
Western Australia & 28 & 11.2 & 18.9 \\
& & $(6.18)$ & $(10.67)$ \\
\hline Overall & 175 & 15.9 & 24.3 \\
& & $(6.78)$ & $(11.04)$ \\
\hline
\end{tabular}

Figure 10.2 shows the distribution of the individual scores of all agencies - again, for each jurisdiction. There is considerable range in the comprehensiveness of agency whistleblowing procedures. A wide range can be found in every jurisdiction, indicating that even those jurisdictions with more detailed legislative frameworks in relation to procedures are not achieving a consistently comprehensive approach.

There are, however, also some notable features. The higher average scores for NSW agencies can be seen in the cluster of NSW agencies at the upper end of the scale. The pattern of the Commonwealth results is also different from the pattern of other jurisdictions, being most widely spread. A significant number is clustered towards the low end of the scale, but there is also a significant number at the high end. Keeping in mind that the Commonwealth agencies included a number outside the APS, with no standard whistleblowing provisions in law, a number of Commonwealth agencies have taken it on themselves to develop procedures that go well beyond legal requirements. Queensland has the largest number of agencies with low scores, notwithstanding - as mentioned earlier - that it has quite comprehensive legislation.

A comparison of the scores for procedures and the size of the organisation, based on information provided in the agency survey, indicates a significant correlation (0.38, $\mathrm{n}=64, \mathrm{p}<0.05)$. This confirms that, across the jurisdictions, more comprehensive whistleblowing procedures are likely to be found in larger organisations. 
Figure 10.2 Comprehensiveness of procedures: distribution of (total) scores by jurisdiction

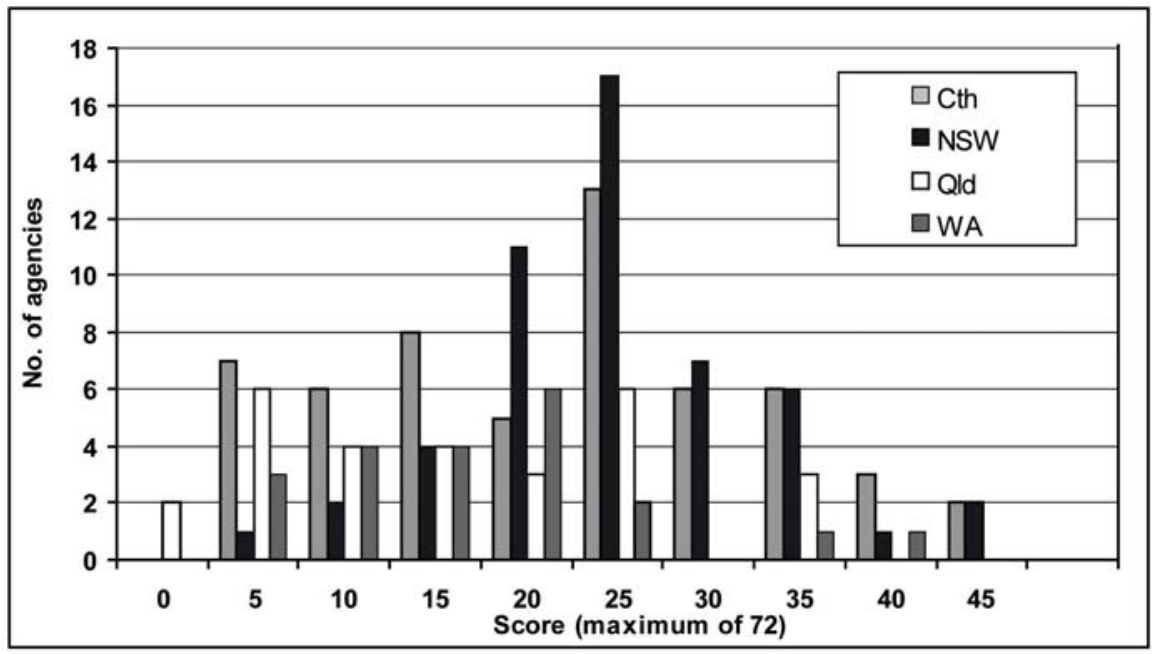

The variability, patchiness and general low comprehensiveness of whistleblowing procedures - on these basic measures - indicates that many agencies have much to learn in relation to the content of their procedures and systems. As outlined in Chapter 1, further analysis as part of the present research is intended to set out lessons for best-practice or model procedures based on the collective experience of Australian public sector agencies so far. A new framework for Internal Witness Management Systems derived from the research so far, reflecting all the items used in the procedures assessment, is provided in Appendix 3.

Two general conclusions can nevertheless be drawn from the current state of whistleblowing procedures in most agencies and jurisdictions. First, where they exist, agencies' formal procedures are skewed towards encouraging reporting and setting in place the investigative responses to those reports, much more than towards the management of the welfare of those involved. In other words, procedures tend to be geared towards meeting the interests of the organisation rather than the needs of the employees who come forward with reports. This bias in the content of procedures suggests that, even when agencies move beyond a mere compliance approach to whistleblowing processes and take up a more utilitarian approach, this can be limited in its focus. Agencies often appear to recognise the practical benefits of reporting from a management perspective without addressing the importance of whistleblower welfare - whether for its practical value in sustaining a positive reporting climate and reducing the costs of conflict or in recognition of other legal and ethical responsibilities towards employees. In the majority of agencies, procedures need substantial review to achieve a more effective balance of approaches. 
Second, the great variability in procedures — such as demonstrated in particular by the clusters of low Queensland and Commonwealth scores - suggests a need for clearer statutory requirements and oversight. Currently, even when legislation provides frameworks aimed at ensuring agencies put in place quality procedures, this is frequently not having its intended effects. Chapter 11 further discusses the need for a new approach to minimum statutory requirements for the content of procedures and for more routine external monitoring of their quality and implementation.

\section{Impact and effectiveness of procedures}

The previous discussion has assumed that comprehensive whistleblowing procedures are desirable because they can and should lead to better outcomes for organisations and whistleblowers. Is there empirical evidence that this is the case?

To answer this question, the results from the employee survey were further analysed for the 102 agencies that had participated in that survey and provided written whistleblowing procedures for assessment. First, the degree of awareness about the existence of the procedures was examined, along with how this awareness appeared to have been achieved and the degree of association between comprehensiveness of procedures, awareness of them and employees' attitudes to whistleblowing and the likely management response. Second, the effectiveness of the procedures was tested for in terms of the same key outcomes identified earlier, including reporting rates and the proportion of employees who said they were treated well or badly as a result. Third, further analysis was conducted to see whether the relationship between procedures and outcomes could be explained with reference to any specific items in the procedures.

\section{Awareness of, and confidence in, procedures}

Across the board, public officials are more aware of the fact that their organisations have procedures relating to whistleblowing than they are of any relevant legislation. When asked whether their organisation had formal policies covering the reporting of wrongdoing, 74 per cent of all employee survey respondents said 'yes', 3 per cent said 'no' and only 22 per cent did not know ( $\mathrm{n}=7663,118$ agencies). Generally, reported knowledge of procedures is widespread in agencies.

It is also clear that higher employee awareness of procedures results directly from management action and the efforts of agencies to embed procedures in their organisation. Of the 231 agencies that responded to the agency survey that they had formal internal disclosure procedures, almost all (229 agencies) indicated they had arrangements in place for informing staff about their policies. The employee survey also asked officials within agencies about the mechanisms by which they had been made aware of the reporting policy of their organisation, 
including via the code of conduct, general training, induction programs and a range of other mechanisms.

The first, though unsurprising, conclusion is that the agencies in which staff awareness of procedures is highest are also those with the most comprehensive procedures rated above. The data reveal a strong and direct correlation between professed knowledge of the existence of procedures and their comprehensiveness in practice $(0.30, \mathrm{n}=101, \mathrm{p}<0.01)$. This result is reassuring in that it shows that more comprehensive procedures are not just fatter documents that then become less likely to have any effect. The reasons for this higher awareness are clear: agencies that have gone to the effort of developing comprehensive procedures also appear to have been most likely to expend resources in making staff aware of them. Organisations with more comprehensive procedures were likely to have used more mechanisms for promoting their contents, with, again, a correlation between larger agency size and greater reported use of different promotional mechanisms (agency survey, 0.26, $\mathrm{n}=79, \mathrm{p}<0.05$ ).

As shown in Table 10.10, there was also a strong association between the comprehensiveness of an agency's awareness-raising approach, in terms of the number of mechanisms used, and two indicators of employee confidence in the procedures: more positive attitudes towards the reporting of wrongdoing generally and greater confidence that management would respond well to reporting if it occurred. Respondents to the internal witness survey also confirmed that the formal internal policies of their organisation played important roles in forming their view of the wrongdoing they went on to report, rating key internal policies second and third (after legislation) out of a list of 10 factors (internal witness survey: Q7).

\section{Table 10.10 Relationship between promotion of procedures and attitudes/expectations about reporting}

\begin{tabular}{ll}
\hline Measure from employee survey & $\begin{array}{l}\text { Correlation with total number of awareness } \\
\text { mechanisms used to promote procedures }\end{array}$ \\
\hline $\begin{array}{l}\text { Attitudes held by staff to reporting of wrongdoing } \\
1=\text { bad and } 5=\text { good }\end{array}$ & $\begin{array}{l}\text { Pearson correlation }=0.36^{*} \\
\text { Significance (two-tailed) }=0.000 \\
\text { ( } n=7436)\end{array}$ \\
$\begin{array}{l}\text { View of staff on how management would respond to } \\
\text { reporting of wrongdoing (Q18 scale) }\end{array}$ & $\begin{array}{l}\text { Pearson correlation }=0.23^{*} \\
1=\text { poor and } 5=\text { well }\end{array}$ \\
(n $=7544)$
\end{tabular}

* Correlation is significant at the 0.01 level

a The awareness mechanism measure runs from 0 (no mechanism nominated) to 16 (all mechanisms nominated). 


\section{Table 10.11 Relationship between comprehensiveness of procedures and employee confidence}

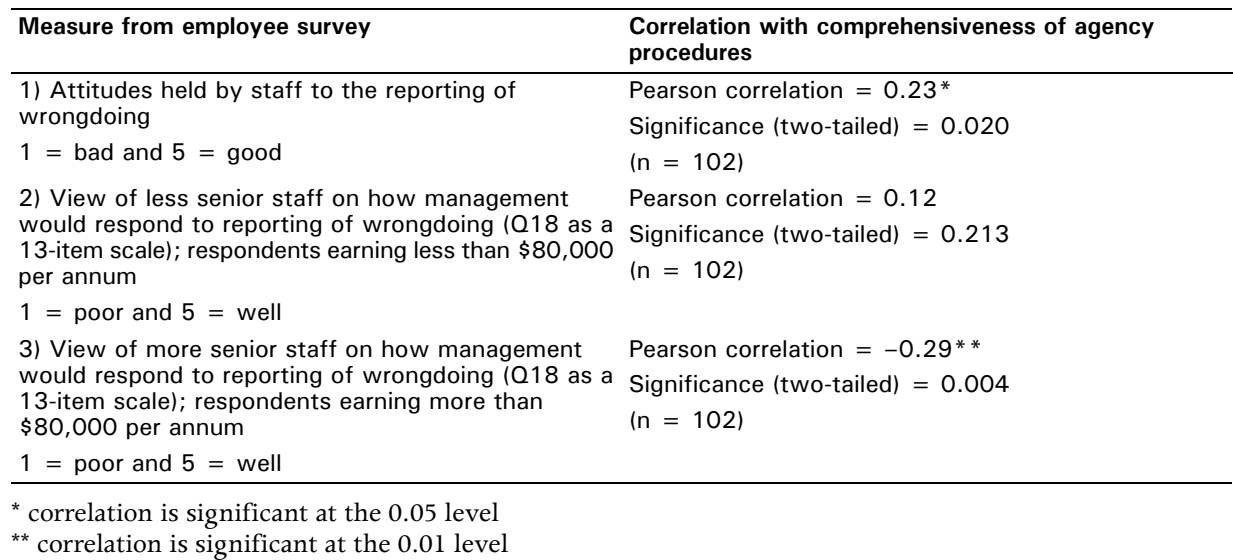

Table 10.11 confirms these results by also showing the direct correlation between more comprehensive procedures and more positive general attitudes to whistleblowing, across the 102 agencies.

The remaining two analyses in Table 10.11, however, show that while awareness might be higher and general attitudes more positive, more comprehensive procedures are not necessarily translating into specific trust on the part of employees about how management will respond if wrongdoing is reported. These analyses provide, in effect, a measure of the level of respondents' confidence that management will deal fairly with reports of whistleblowing and protect employees from reprisals. The third analysis examines the relationship between comprehensiveness of procedures and trust in the management response to whistleblowing for less senior employees (earning less than $\$ 80,000$ per annum); there was no significant relationship. In other words, even if more comprehensive procedures improve the general outlook of employees towards whistleblowing, they do not appear to lead to higher employee confidence in the management response. One reason could be that employees do not become fully aware of the procedures until such time as they are contemplating reporting. It could, however, also be that staff members are aware of the relative weakness of most procedures in areas of real, effective protection and support. Certainly, staff members are not yet convinced about these elements, even if they are otherwise predisposed to report.

The fourth analysis shows a particularly troubling result. It shows the same analysis for more senior employees (earning \$80,000 or more per annum). Consistent with the results in Chapter 7 , more senior staff showed greater overall confidence in the management of their organisations to deal fairly with reports of whistleblowing (mean 3.35, $\mathrm{n}=3619$ ) compared with the less senior staff (mean 3.25, $\mathrm{n}=3838$ ). This difference was significant at the 0.001 level. The 
higher confidence of more senior staff in their agencies' procedures did not, however, tend to be a feature of agencies with comprehensive procedures, but rather of agencies with weaker procedures. In other words, there was a strong negative correlation between comprehensiveness of procedures and the confidence of more senior staff in the likely management response. Senior staff members were more confident about the management response in agencies with less comprehensive procedures and less confident about the response in those agencies with stronger procedures. In some circumstances, managers even reported high levels of confidence in the organisation's capacity to deal with reporting of wrongdoing when the organisation had no whistleblowing procedures at all.

What might explain this perverse result? Comments received on this result, when initially published, suggested as one explanation (called an 'ill-intentioned agency' hypothesis) that managers might be confident in their procedures specifically because they knew them to be weak. In other words, managers were aware that the procedures did not provide proper systems for reporting or effective protection to employees - and believed this was the right way for management to handle whistleblowing. This hypothesis was not, however, consistent with the nature of the 13 survey items making up the relevant scale (employee survey: Q18), which meant that these respondents were explicitly professing confidence that the responses would be favourable to whistleblowers, even when no procedures were in place for this.

Consequently, the more logical explanations - while still troubling - are that senior staff have low knowledge of the real contents of their own systems and procedures and/or do not know whether what they contain is valuable or not. In other words, their confidence is simply misplaced. Evidence of this mismatch between the content of procedures and perceptions of their adequacy was also present among managers and case-handlers in the case study agencies. Case-handlers and managers were surveyed about whether they believed their agencies' whistleblowing policies gave employees 'a reasonable idea about what is going to happen' when they reported wrongdoing. The results for 10 of these agencies are presented in Table 10.12, alongside their score for the comprehensiveness of their real procedures. The data show that case-handlers and managers are generally positive about the usefulness of their procedures. In some cases, however, they appeared to be concerned about their procedures when they were really relatively comprehensive; and, in other cases (especially NSW agency C, bolded), the procedures were poor but case-handlers and managers thought they were useful. 
Table 10.12 Usefulness of procedures for employees contemplating reporting

\begin{tabular}{lccc}
\hline Case-study agency & $\begin{array}{c}\text { Comprehensiveness score } \\
\text { for agency procedures (max. } \\
\text { 72) }\end{array}$ & $\begin{array}{c}\text { Percentage of case-handlers } \\
\text { agreeing on usefulness }\end{array}$ & $\begin{array}{c}\text { Percentage of managers } \\
\text { agreeing on usefulness }\end{array}$ \\
\hline Commonwealth & 45 & $80.8(\mathrm{n}=26)$ & $81.3(\mathrm{n}=32)$ \\
A & 37 & $60.9(\mathrm{n}=23)$ & $50.0(\mathrm{n}=28)$ \\
B & 46 & $89.1(\mathrm{n}=55)$ & $83.8(\mathrm{n}=43)$ \\
C & & & \\
\hline New South Wales & 46 & $87.5(\mathrm{n}=24)$ & $96.4(\mathrm{n}=28)$ \\
A & 41 & $87.5(\mathrm{n}=16)$ & $64.3(\mathrm{n}=14)$ \\
B & 25 & $80.0(\mathrm{n}=5)$ & $90.0(\mathrm{n}=30)$ \\
C & 30 & $50.0(\mathrm{n}=24)$ & $80.0(\mathrm{n}=40)$ \\
\hline Queensland & 26 & $75.0(\mathrm{n}=4)$ & $70.0(\mathrm{n}=10)$ \\
A & & & $81.0(\mathrm{n}=21)$ \\
B & 45 & $76.9(\mathrm{n}=26)$ & $70.6(\mathrm{n}=34)$ \\
\hline Western Australia & 41 &
\end{tabular}

Sources: Case-handler and manager surveys: Q17.

In the same agencies, the internal witnesses were less positive about the usefulness of the written procedures when it came to the process thereafter. Although 79 per cent of case-handlers and managers believed that their procedures gave employees a reasonable idea about what was going to happen, only 50 per cent of internal witnesses said this was really the case (internal witness survey: Q12; $\mathrm{n}=193$ ). This is a further sign that while comprehensive procedures do make a difference, there are contradictory assessments within agencies about their current adequacy.

In summary, in some agencies, more senior staff members appear to be excessively optimistic about how well the organisation's procedures are likely to deal with the reporting of wrongdoing. This finding brings further light to bear on the gap between broad principles and practical realities in relation to managerial awareness of legislative obligations, identified in Chapter 7 , in the context of the broadly positive outlook of managers. It reinforces the need for systematic review and greater statutory guidance, since it suggests that even if procedural approaches are having discernable effects - positive or negative - more senior staff members currently have only a very limited grasp of their relative quality or what these effects might be.

\section{Impact and effectiveness}

The most crucial issue is whether more comprehensive procedures are positively associated with better substantive outcomes, in terms of the level of actual reporting behaviour and the treatment of whistleblowers. The relationships between the comprehensiveness of procedures and these outcomes are shown in Table 10.13. 
The first analysis shows a positive relationship, although not necessarily strong, between comprehensive procedures and a higher level of reporting. Earlier, there was no evidence that awareness of or confidence in legislation directly increased reporting behaviour, but there was evidence that it reduced the incidence of employees observing serious wrongdoing and doing nothing. Here, there is a modest positive relationship between the comprehensiveness of an agency's procedures and the proportion of staff members who report the serious wrongdoing they observe. Given the evidence in Chapter 3 about the complexity of reporting behaviour, it would be unlikely that the comprehensiveness of agency procedures was the sole or direct determinant of whether an employee blew the whistle. Large proportions of employees still report wrongdoing in agencies with no or poor procedures. Nevertheless, this result provides an indication that comprehensive procedures provide positive reinforcement for reporting and it is particularly likely that they also shape how employees report.

Table 10.13 Relationship between comprehensiveness of procedures and key outcomes (agencies)

\begin{tabular}{|c|c|}
\hline Measure from employee survey & $\begin{array}{l}\text { Correlation with comprehensiveness of agency } \\
\text { procedures }\end{array}$ \\
\hline $\begin{array}{l}\text { 1) Reporting rate: proportion of respondents who } \\
\text { observed wrongdoing they believed to be } \\
\text { very/extremely serious and reported it (Q26) }\end{array}$ & $\begin{array}{l}\text { Pearson correlation }=0.20^{*} \\
\text { Significance (two-tailed) }=0.043 \\
(\mathrm{n}=102)\end{array}$ \\
\hline $\begin{array}{l}\text { 2) Proportion of all non-role reporters who rated } \\
\text { treatment by management as 'bad' or 'extremely bad' } \\
(030)^{\mathrm{a}}\end{array}$ & $\begin{array}{l}\text { Pearson correlation }=-0.39 * * \\
\text { Significance (two-tailed) }=0.008 \\
(n=45)\end{array}$ \\
\hline $\begin{array}{l}\text { 3) Proportion of all non-role reporters who rated } \\
\text { treatment by co-workers as 'bad' or 'extremely bad' } \\
(\mathrm{Q} 31)^{\mathrm{a}}\end{array}$ & $\begin{array}{l}\text { Pearson correlation }=-0.34^{*} \\
\text { Significance (two-tailed) }=0.026 \\
(n=44)\end{array}$ \\
\hline
\end{tabular}

* correlation is significant at the 0.05 level

** correlation is significant at the 0.01 level

a It was anticipated that these correlations would be negative because these outcome scales run from a good outcome scoring lowest to a poor outcome scoring highest.

The second and third analyses in Table 10.13 also show positive results. Respectively, they show the relationship between comprehensiveness of an agency's procedures and the proportion of non-role reporters (whistleblowers) in the agency who indicated they were treated badly by management or by co-workers. As with other analyses, organisations in which fewer than 10 participants responded to the relevant measures were omitted from the calculations, meaning the presence of any relationship could be tested in only 45 and 44 agencies respectively.

The analysis shows a strong relationship between the comprehensiveness of procedures and better treatment by management and a weaker, but still statistically significant, relationship between the comprehensiveness of procedures and better treatment by co-workers. This is a major finding, supporting the conclusion that when an organisation has comprehensive 
procedures, there is more likely to be a positive outcome in terms of treatment and protection for the person who reported. The remaining question is why this is the case, given that, across the board, procedures are weak in the area of whistleblower protection and support.

\section{Evaluating specific areas of the procedures}

Up to this stage, relationships have been examined in relation to the comprehensiveness of the procedures in their totality. The comprehensiveness of the procedures was, however, assessed on 24 individual items, as described in Table 10.8. The weakest areas were those associated with whistleblower protection and support. Depending on the specific areas of relative strength, an agency's procedures could still show as relatively comprehensive overall without necessarily indicating any particular strength on issues relating to protection and support. In other words, the procedures themselves might not explain why more comprehensive procedures correlated with better treatment outcomes.

The analysis was therefore taken to a further stage, looking for correlations between the various outcome measures above and specific items in the procedures. Table 10.14 identifies the nine items in the written procedures that were more likely to be present when better treatment by managers, better treatment by co-workers or more positive attitudes to reporting were indicated by the employee survey respondents from the agency concerned. Notably, three of the items (bolded) relate directly to the protection of internal witnesses, even though these were the items least commonly present in most agency procedures, as indicated in Table 10.8.

The correlations with these particular items were not, however, strong. This tends to reinforce that in addition to being weakly represented across the board - at least in so far as they are described in written procedures - systems for actively protecting and managing internal witnesses do not currently seem to explain why some agencies achieve better outcomes. There is a correlation with comprehensive procedures, but the better outcomes experienced by whistleblowers in these agencies could have more to do with other factors also consistent with the attempt to be more comprehensive, such as overall management commitment to fairness and equity, than to specific systems and policies for managing whistleblowers. Agencies that manage to protect more whistleblowers could even be doing so despite a lack of effective systems, rather than because of them. 
Table 10.14 Relationship between content of procedures and key outcomes (correlations)

\begin{tabular}{|c|c|c|c|}
\hline $\begin{array}{l}\text { Procedure assessment item/topic } \\
\text { (numbers indicate rank order in Table 10.8) }\end{array}$ & $\begin{array}{l}\text { Treatment by } \\
\text { management }\end{array}$ & $\begin{array}{l}\text { Treatment by } \\
\text { co-workers }\end{array}$ & $\begin{array}{l}\text { Attitude to } \\
\text { reporting }\end{array}$ \\
\hline $\begin{array}{l}\text { 4. Types of concerns for which it is appropriate } \\
\text { to use the whistleblowing mechanism }\end{array}$ & $-0.48 * *$ & $-0.30 *$ & 0.08 \\
\hline 11. Commitment to principle of whistleblowing & $-0.40 * *$ & $-0.33^{*}$ & 0.22 \\
\hline 5. Information about legislation & $-0.37 *$ & $-0.42 * *$ & 0.02 \\
\hline $\begin{array}{l}\text { 10. Roles and responsibilities of the key players } \\
\text { in the organisation's whistleblowing arrangements }\end{array}$ & -0.28 & $-0.38^{*}$ & 0.08 \\
\hline $\begin{array}{l}\text { 2. To whom and how whistleblowing concerns } \\
\text { can be directed internally }\end{array}$ & $-0.37 *$ & -0.23 & 0.14 \\
\hline $\begin{array}{l}\text { 17. Active management and support of internal } \\
\text { witnesses }\end{array}$ & -0.19 & $-0.33^{*}$ & $0.29 * *$ \\
\hline $\begin{array}{l}\text { 7. To whom and how whistleblowing concerns } \\
\text { can be directed (externally) and in what } \\
\text { circumstances }\end{array}$ & $-0.30 *$ & -0.29 & 0.00 \\
\hline $\begin{array}{l}\text { 22. Rights of the internal witness to request } \\
\text { positive action by the entity to protect them }\end{array}$ & -0.01 & 0.01 & $0.31 * *$ \\
\hline $\begin{array}{l}\text { 24. Procedures for the assessment of risk of } \\
\text { reprisal against individual whistleblowers }\end{array}$ & -0.11 & -0.11 & $0.25 *$ \\
\hline
\end{tabular}

* correlation is significant at the 0.05 level

** correlation is significant at the 0.01 level

Notes: Correlations on the outcome analyses are negative because the outcome scales run from a good outcome scoring lowest to a poor outcome scoring highest. The procedural analysis ratings run from poor procedures scoring lowest to good procedures scoring highest.

Sources: Procedures assessment and employee survey.

\section{Discussion and conclusions}

Public sector organisations almost universally react to difficult workplace issues by developing and implementing sets of procedures. Every public sector organisation has many volumes of these procedures. It is not surprising that these will usually include procedures for the sensitive and difficult area of the reporting of wrongdoing. It is also not surprising that the difficulty of the area will lead to widespread uncertainty regarding the appropriate content for procedures and doubts regarding their effectiveness.

This analysis has, however, demonstrated empirically that the effort put into developing and implementing more comprehensive whistleblowing procedures is worthwhile. There are strong indications that comprehensive procedures help raise confidence that the organisation will deal with reports effectively and sensitively and will encourage reporting. Comprehensive procedures are also associated with better outcomes for those staff who do report. In particular, comprehensive procedures for the reporting of wrongdoing and the protection of whistleblowers are associated with good outcomes, as indicated by the measures of how internal witnesses are treated by management and their co-workers. Besides engendering good outcomes, comprehensive procedures are strongly associated with the encouragement of staff to come forward. Legislation itself also appears to have clear positive effects, although these could 
also relate to elevated expectations of good treatment by management, which might or might not necessarily pan out in practice.

This chapter has nevertheless also shown some serious weaknesses in procedures and conflicting assessments of the adequacy of procedures at different levels in agencies. A surprising and troubling result was a negative relationship between the comprehensiveness of the procedures and the confidence of more senior staff in the likely response of management to whistleblowing. More-senior staff (such as managers) often appeared to have either overly optimistic or pessimistic views of their own procedures, depending on the case. In either case, their views appeared to be somewhat disconnected from the reality, particularly since the views of less-senior staff tended to correlate more directly with the real quality of the procedures.

The analysis of which procedural items were most commonly present when the outcomes were positive, and when the attitude to reporting wrongdoing was positive, enables a tentative conclusion about which elements of the procedures were most important to staff. Some of those elements relate to the way in which organisations handle reprisals. The analysis of procedures indicated that, overall, this was the weakest area in reporting procedures and one in which organisations could make significant improvements. While more comprehensive procedures correlated with better outcomes, these were not necessarily explained by the contents of the procedures themselves on the relevant issues.

This evaluation of the whistleblowing procedures of individual organisations has essentially been a measure of the completeness of written documents. While the evaluation in this chapter has attempted to include all relevant procedural elements relating to whistleblowing, there are many other issues involved in the effective handling of wrongdoing besides the completeness of written procedures. Clearly, procedures alone do not guarantee a good outcome; this is likely to hinge on management commitment, promulgation of the procedures and effective resources devoted to investigation and to supporting staff. Nevertheless, the evidence suggests that these factors are also more likely to be present in those organisations that take the trouble to develop more comprehensive whistleblowing procedures, which appear to reflect at least some aspects of organisational practices.

The second report from the present research will describe, in greater qualitative detail, the direct relationships between agencies' procedures, operational systems and outcomes from whistleblowing. Using the framework already developed and provided in Appendix 3, this further research will support a clearer picture of current and potential best practice in systems for managing the reporting of wrongdoing. As it stands, while most agencies in most jurisdictions are yet to move beyond a mere compliance approach to whistleblowing procedures, there is clear evidence that such movement is necessary and potentially rewarding. 
As more senior managers move to recognise the utility of good whistleblowing systems, as well as their legal and ethical responsibilities to ensure the welfare of their own employees, the value of a more comprehensive approach to whistleblowing is likely to be immense.

\section{ENDNOTES}

1 The author thanks Jane Olsen for conducting some of the analyses in this chapter, and A. J. Brown for editorial guidance and direction. Particular thanks also to the other members of the research team who participated in the task of coding the procedures for assessment, as described in the third part of the chapter: Lindy Annakin, Marika Donkin, Dr Michael Carrel and Dr Yasmine Fauzee. 